\title{
Pengaruh Mutasi dan Pengembangan Karir Terhadap Semangat Kerja Pegawai pada Dinas Pengendalian Penduduk, Keluarga Berencana, Pemberdayaan Perempuan dan Anak (DPPKBP3A) Kota Gorontalo
}

\author{
Zulkarnain Ilyas Idris ${ }^{1}$
}

Universitas Ichsan. Email; izul.alidris@gmail.com

\section{ARTICLES INFORMATION}

\section{ABSTRACT}

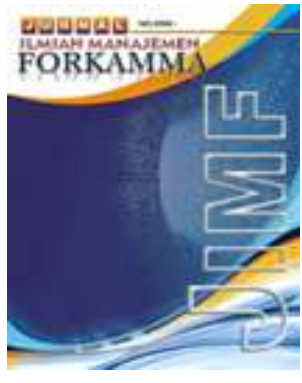

\section{JURNAL ILMIAH MANAJEMEN FORKAMMA}

Vol.4, No.3, Juli 2021 Halaman : 288- 297

(C) LPPM \& FORKAMMA

Prodi Magister Manajemen UNVERSITAS PAMULANG

ISSN (online) : 2599-171X ISSN (print) : :2598-9545

Keyword :

Mutasi; Pengembangan Karir; Semangat Kerja

JEL. classification :

O15,

Contact Author :

PRODI

MAGISTER MANAJEMEN \& FORKAMMA UNPAM

JL.Surya Kencana No.1 Pamulang

Tangerang Selatan - Banten

Telp. (021) 7412566, Fax (021) 7412491 Email :

jurnalforkamma.unpam@gmail.com

\begin{abstract}
Abstrak. Riset yang dilaksanakan di Dinas pengendalian penduduk, keluarga berencana, pemberdayaan perempuan dan anak (DPPKB3A) Kota Gorontalo tentunya ingin mengetahui pengaruhnya secara simultan (bersama) dan parsial (sendirisendiri) variabel Mutasi dan variabel Pengembangan Karir terhadap Semangat Kerja. Populasi dan sampel mengambil responden sebanyak 53 orang sehingga teknik pengambilan populasi dan sampel disebut teknik pengambilan sensus. Pengumpulan data melalui beberapa item-item yang menjadi pernyataan dan lewat pengujian validitas dan reliabilitas yang menjadi instrumen pada riset tersebut. Pada riset tersebut metode analisis jalur (path analysis) menjadi alat yang digunakan. Hipotesis membuktikan Pengujian simultansi pengaruh mutasi dan pengembangan karir terhadap semangat kerja pegawai berpengaruh signifikan sebesar 78,2 \%. Sedangkan secara parsial efek mutasi berpengaruh signifikan terhadap semangat pegawai sebesar 38,6 \% dan pengembangan karir berpengaruh signifikan terhadap semangat kerja sebesar $35,3 \%$.
\end{abstract}

Keywords: Mutasi; Pengembangan Karir; Semangat Kerja

\begin{abstract}
Research conducted at the Department of Population Control, Family Planning, Women and Children Empowerment (DPPKB3A) Gorontalo City certainly wants to know the effect simultaneously (together) and partially (alone) on the Mutation variable and the Career Development variable on Work Spirit. The population and samples took as many as 53 respondents so that the population and sample collection techniques were called census taking techniques. Collecting data through several items that become statements and through testing the validity and reliability of the instruments in the research. In this research, the path analysis method is the tool used. The hypothesis proves that the simultaneous test of the effect of mutation and career development on employee morale has a significant effect of $78.2 \%$. While partially the mutation effect has a significant effect on employee morale by $38.6 \%$ and career development has a significant effect on work morale by $35.3 \%$.
\end{abstract}

Keywords: Mutation; Career Development; Work Spirit 


\section{A. PENDAHULUAN}

Kemampuan manusia untuk bekerja tentunya merupakan kemampuanya dalam intelektual dan kemampuan keterampilan sebagai modal manusia dalam meningkatkan kualitas roda organisasi yang memiliki sasaran tertentu. Pada organisasi pemerintahan sasaran utamanya adalah pelayanan kepada masyarakat. Oleh karena itu dalam struktur organisasi pemerintahan para pegawai merupakan aset berharga dalam mengatur tata kelola pemerintahan. Tentunya dalam organisasi pemerintahan para pegawai sebagai pelayan masyarakat dituntut untuk semangat dalam menjalankan tugas-tugas yang diamanahkan kepada setiap pegawai.

Semangat kerja pegawai dalam menjalankan tugas adalah bagian terpenting guna mencapai visi dan misi organisasi dalam menghadapi tantangan zaman. Para pegawai akan lebih semangat bekerja dan dapat menyelesaikan pekerjaan yang diperintahkan oleh atasan jika atasan juga bersikap memperhatikan kehidupan pegawai tersebut dengan cara memperhatikan karir pegawainya, karena dengan memperhatikan karir bawahanya maka pegawai akan ada kecenderunganya untuk bekerja lebih semangat dalam menyelesaikan tugas-tugasnya. Objek riset ini dilaksanakan di Dinas pengendalian penduduk, keluarga berencana, pemberdayaan perempuan dan anak (DPPKB3A) Kota Gorontalo dimana fenomena yang terjadi adanya semangat kerja pegawai mengalami penurunan. Hal ini terjadi karena dalam melakukan mutasi pegawai tidak melihat dari profesionalisme pekerjaan. Dimana adanya mutasi dalam koridor kenaikan jabatan hanya mengedepankan faktor orang dekat. Selain itu banyak dari kalangan yang menduduki jabatan tertentu dipindahkan ketempat yang tidak diinginkan akibat dari korban politik sehingganya membuat semangat kerja pegawai mengalami penurunan. Dalam pengembangan karir pegawai pihak organisasi banyak mempertimbangkan pegawai untuk dipromosikan jabatanya dimasa yang akan datang karena pegawai walaupun berusaha untuk merencanakan karirnya tidak serta merta langsung diangkat untuk menduduki jabatan tertentu tetapi hanya ada orang dekat dari pejabat yang diposisikan pada jabatan tertentu. Tentunya dengan kejadian seperti ini pegawai tidak memiliki semangat lagi dalam menjalankan tugasnya. Pegawai menghrapkan dengan adanya mutasi dan perhatian organisasi dalam pengembangan karir pegawai dapat memberikan kepada mereka peluang untuk maju sehingga imbasnya adalah semangat kerja mereka mengalami peningkatan. Sebagaimana Agustini (Manihuruk, dkk, 2020:297) menjelaskan bahwa income, merasakan aman, dan suasana kerja adalah merupakan faktor penentu semangat kerja seseorang. Rumusan masalah penelitian ini, berapa besarkah efek mutasi dan pengembangan karir yang dilihat secara simultan terhadap semangat kerja $(Y)$ pegawai di Dinas pengendalian penduduk, keluarga berencana, pemberdayaan perempuan dan anak (DPPKB3A) Kota Gorontalo. berapa besarkah efek mutasi (X1) yang dilihat secara parsial terhadap semangat kerja $(\mathrm{Y})$ pegawai di Dinas pengendalian penduduk, keluarga berencana, pemberdayaan perempuan dan anak (DPPKB3A) Kota Gorontalo. berapa besarkah efek pengembangan karir (X2) yang dilihat secara parsial terhadap semangat kerja $(Y)$ pegawai di Dinas pengendalian penduduk, keluarga berencana, pemberdayaan perempuan dan anak (DPPKB3A) Kota Gorontalo.

Dari rumusan masalah diatas sehingga disusunlah tujuan penelitian ini yaitu agar kita tahu besarnya efek mutasi (X1) dan Pengembangan karir (X2) yang dilihat secara simultan terhadap semangat kerja $(Y)$ pegawai di Dinas pengendalian penduduk, keluarga berencana, pemberdayaan perempuan dan anak (DPPKB3A) Kota Gorontalo. agar kita tahu besarnya efek mutasi (X1) yang dilihat secara parsial terhadap semangat kerja (Y) pegawai di Dinas pengendalian penduduk, keluarga berencana, pemberdayaan perempuan dan anak (DPPKB3A) Kota Gorontalo. Agar kita tahu besarnya efek pengembangan karir (X2) yang dilihat secara parsial terhadap semangat kerja (Y) 
pegawai di Dinas pengendalian penduduk, keluarga berencana, pemberdayaan perempuan dan anak (DPPKB3A) Kota Gorontalo.

\section{B. KAJIAN LITERATUR}

\section{Mutasi}

Martoyo (Judas, 2013:1221) mengemukakan bahwa mutasi adalah perpindahan posisi satu keposisi lain baik jabatan maupun tempat pekerjaan yang dilaksanakan baik secara garis lurus vertikal maupun horizontal didalam suatu wadah organisasi. Bagi Sedarmayanti (Pramuditha, 2020:135) bahwa Mutasi adalah kegiatan yang merupakan serangkaian proses untuk mengembangkan keadaan posisi atau status dari pegawai dalam struktur organisasi. Kemudian mutasi menurut Wahyudi (Badriyah, 2015:216) merupakan rangkaian tugas seseorang yang berpindah untuk suatu level yang sejajar dari posisi kerja yang sebelumnya merasakan perpindahan pekerjaan.

Nitisemito (Ambarita, dkk, 2015:528) menjelaskan mutasi adalah suatu aktivitas kerja dari seorang atasan dalam perusahaan yang memiliki kewenangan terhadap karyawan untuk dipindahkan dari suatu pekerjaan satu kepekerjaan yang lainya. Bagi Samsudin (2006:254) mutasi merupakan suatu serangkaian kegiatan yang memiliki korelasi dengan serangkaian suatu fungsi pemindahan, status tenaga kerja, dan rasa bertanggung jawab ketempat tertentu agar supaya pegawai tersebut dapat memperoleh suatu kepuasan dalam pekerjaanya sehingga ujungnya akan memberikan prestasi yang maksimal pada organisasi.

\section{Pengembangan Karir}

Menurut Handoko (Negara, 2014:2) menjelaskan pengembangan karir merupakan seseorang secara pribadi merencanakan karirnya sehingga terjadi peningkatan karir demi mencapai suatu tujuan. Sedangkan Marwansyah (Marpaung, 2018:80) menjelaskan Pengembangan karir adalah rangkaian kegiatan dalam mengembangkan dirinya untuk melakukan suatu perencanaan karirnya.

Siagian (Wardana, dkk, 2015:4) menuturkan bahwa pengembangan karir adalah suatu gambaran yang tidak abstrak bagi setiap tenaga kerja untuk menggapai puncak anak tangga .yang dapat dijangkau melalui tampilan kerja-kerjanya yang dapat memberikan kepuasan. Sedangkan Russel, dkk (Rosidah, 2009:227) Pengembangan karir, Rencana yang terorganisir secara formal dalam mencapai suasana yang seimbang antara kepentingan karir secara pribadi dan kepentingan karir secara lembaga yang terorganisir dalam organisasi.

Mondy (Priansa, 2016:161) menyatakan bahwa pengembangan karir ialah dimana organisasi menggunakan pendekatan dengan cara formal dimana tenaga kerja dibutuhkan sesuai dengan klasifikasi dan pengalaman. Pengembangan karir adalah dimana seseorang dengan status dan jenjangnya dalam suatu pekerjaan mendapatkan dorongan lewat kepribadianya yang menyangkut dengan pendidikan dan pengalamanya (Widodo, 2015:114).

\section{Semangat Kerja}

Menurut Sastrohadiwiryo (Purwaningrum, dkk, 2014:4) menjelaskan bahwa Semangat kerja merupakan sikap tenaga kerja secara person atau kelompok dimana pada diri tenega kerja tercipta kebahagiaan secara bathin yang mendalam dalam melaksanakan aktivitas pekerjaan pada ketetapan-ketetapan perusahaan. Sedangkan menurut Pangabean (Ratnasari, dkk, 2017:102) Semangat kerja adalah suasana kelompok memiliki arah yang tidak abstrak dan statis sehingga tujuan setiap person dapat dirasakan menjadi suatu hal yang sangat penting.

Semangat kerja menurut Tohardi (Permaningratna, 2013:3) adalah pekerjaan yang dilaksanakan lebih ekstra sehingga harapanya tugas yang diemban tersebut akan lebih 
baik dan lebih cepat. Sedangkan Hasanah (Sari, 2020:55) mengungkapkan semangat kerja adalah kemampuan individu dalam suatu kelompok untuk menciptakan team work sebagai upaya dalam mencapai suatu tujuan.

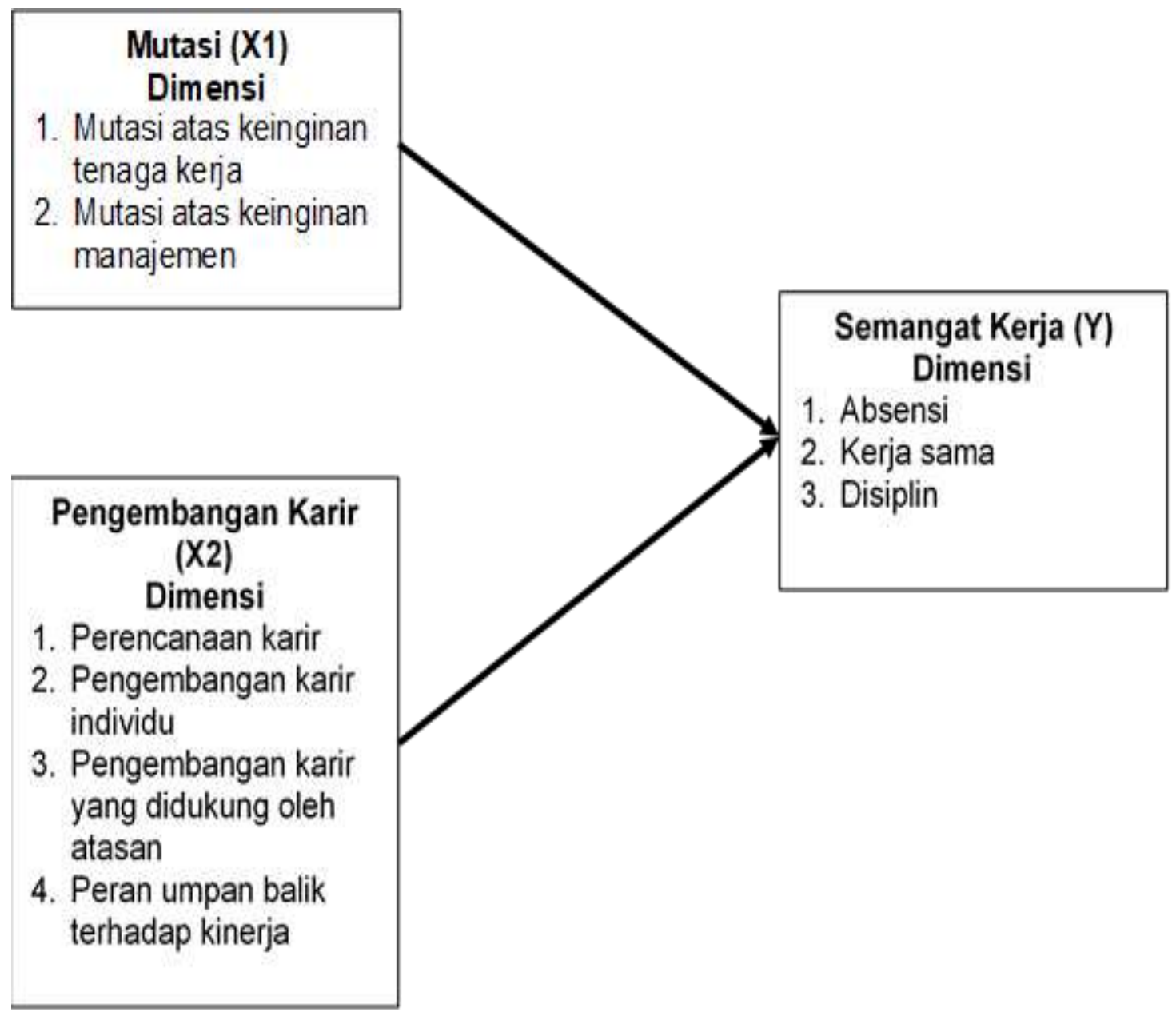

Sumber : Rivai dan Sagala (Priansa, 2016:161)

\section{Gambar 1 Kerangka Berfikir}

\section{METODOLOGI PENELITIAN}

Penggunaan metode dalam riset ini adalah quantitative method (Metode kuantitatif) Metode yang didasarkan pada penelitian filsafat positivisme dimana dalam melakukan penelitian menggunakan populasi dan sampel, metode menggunakan angka-angka statistik dalam melakukan analisis (Sugiono, 2010:65). Dalam mengumpulkan data digunakan metode survei. Metode survei itu sendiri menjabarkan tentang hubungan kausalitas pada pengujian hipotesis baik riset tersebut dilaksanakan pada skala populasi kecil maupun besar (Sugiono, 2010:68). Dalam penggunaan data ini bersumber dari data primer, dimana data primer tersebut merupakan cara untuk pengambilan sampel dengan menggunakan kuisoner sebagai data yang menjadi data utama. Populasi yang dijadikan responden pada penelitian ini adalah seluruh pegawai pada kantor Dinas Pengendalian Penduduk, Keluarga Berencana, Pemberdayaan Perempuan dan Anak (DPPKBP3A) Kota Gorontalo yang berjumlah 53 responden. Riset ini dalam menganalisis data menggunakan path analysis yang pada awalnya data dikonversi dari ordinal ke interval. 


\section{HASIL DAN PEMBAHASAN}

1. Mengukur Uji Validitas dan Reliabilitas Variabel Mutasi (X1)

Tabel 1 : Hasil Uji Validitas dan Reliabilitas Variabel Mutasi (X1)

\begin{tabular}{|c|c|c|c|c|c|c|}
\hline \multirow{2}{*}{ Item } & \multicolumn{3}{|c|}{ Uji Validitas } & \multirow[t]{2}{*}{$\begin{array}{c}\text { Nilai } \\
\text { Signifikansi }\end{array}$} & \multicolumn{2}{|c|}{ Uji Reliabilitas } \\
\hline & $r_{\text {Hitung }}$ & $r_{\text {table }}$ & Ket & & Alpha & Ket \\
\hline X1.1 & 0,508 & 0,228 & Valid & 0,000 & \multirow{6}{*}{0,619} & \multirow{6}{*}{$\begin{array}{l}>0,6= \\
\text { reliable }\end{array}$} \\
\hline X1.2 & 0,631 & 0,228 & Valid & 0,000 & & \\
\hline $\mathrm{X} 1.3$ & 0,619 & 0,228 & Valid & 0,000 & & \\
\hline $\mathrm{X} 1.4$ & 0,618 & 0,228 & Valid & 0,000 & & \\
\hline $\mathrm{X} 1.5$ & 0,521 & 0,228 & Valid & 0,000 & & \\
\hline$\times 1.6$ & 0,460 & 0,228 & Valid & 0,000 & & \\
\hline
\end{tabular}

Sumber: Data Olahan 2021

Dari hasil uji validitas dan reliabilitas variabel mutasi (X1) menunjukkan semua item baik X1.1 sampai dengan X1.6 dikatakan valid sebab nilai r-hitung lebih besar dari pada nilai r-tabel dan dikatakan reliable karena Cronbach's Alpha >0,60.

\section{Mengukur Uji Validitas dan Reliabilitas Variabel Pengembangan Karir (X2)}

Tabel 2 : Hasil Uji Validitas dan Reliabilitas Variabel Pengembangan Karir (X2)

\begin{tabular}{|c|c|c|c|c|c|c|}
\hline \multirow{2}{*}{ Item } & \multicolumn{3}{|c|}{ Uji Validitas } & \multirow[t]{2}{*}{$\begin{array}{c}\text { Nilai } \\
\text { Signifikansi }\end{array}$} & \multicolumn{2}{|c|}{ Uji Reliabilitas } \\
\hline & $r_{\text {Hitung }}$ & $r_{\text {table }}$ & Ket & & Alpha & Ket \\
\hline X2.1 & 0,302 & 0,228 & Valid & 0,000 & \multirow{7}{*}{0,646} & \multirow{7}{*}{$\begin{array}{l}>0,6= \\
\text { reliable }\end{array}$} \\
\hline$\times 2.2$ & 0,648 & 0,228 & Valid & 0,000 & & \\
\hline $\mathrm{X} 2.3$ & 0,539 & 0,228 & Valid & 0,000 & & \\
\hline$\times 2.4$ & 0,431 & 0,228 & Valid & 0,000 & & \\
\hline$\times 2.5$ & 0,492 & 0,228 & Valid & 0,000 & & \\
\hline$X 2.6$ & 0,575 & 0,228 & Valid & 0,000 & & \\
\hline $\mathrm{X} 2.7$ & 0,632 & 0,228 & Valid & 0,000 & & \\
\hline
\end{tabular}

Sumber: Data Olahan 2021

Dari uji validitas dan reliabilitas pengembangan karir (X2) semua item baik X2.1 sampai dengan X2.7 dapat dikatakan valid karena nilai r-hitung lebih besar dari pada nilai r-tabel dan dikatakan reliable karena Cronbach's Alpha $>0,60$. 
3. Mengukur Uji Validitas dan Reliabilitas Variabel Semangat Kerja (Y)

Tabel 3 : Hasil Uji Validitas dan Reliabilitas Variabel Semangat Kerja (Y)

\begin{tabular}{|c|c|c|c|c|c|c|}
\hline \multirow{2}{*}{ Item } & \multicolumn{3}{|c|}{ Uji Validitas } & \multirow[t]{2}{*}{$\begin{array}{c}\text { Nilai } \\
\text { Signifikansi }\end{array}$} & \multicolumn{2}{|c|}{ Uji Reliabilitas } \\
\hline & $r_{\text {Hitung }}$ & $r_{\text {table }}$ & Ket & & Alpha & Ket \\
\hline Y1.1 & 0,302 & 0,228 & Valid & 0,000 & \multirow{8}{*}{0,650} & \multirow{8}{*}{$\begin{array}{l}>0,6= \\
\text { reliable }\end{array}$} \\
\hline$\overline{Y 1.2}$ & 0,648 & 0,228 & Valid & 0,000 & & \\
\hline Y1.3 & 0,539 & 0,228 & Valid & 0,000 & & \\
\hline Y1.4 & 0,431 & 0,228 & Valid & 0,000 & & \\
\hline Y1.5 & 0,492 & 0,228 & Valid & 0,000 & & \\
\hline$\overline{Y 1.6}$ & 0,575 & 0,228 & Valid & 0,000 & & \\
\hline Y1.7 & 0,430 & 0,228 & Valid & 0,000 & & \\
\hline Y1.8 & 0,442 & 0,228 & Valid & 0,000 & & \\
\hline
\end{tabular}

\section{Sumber: Data Olahan 2021}

Dari ukuran uji validitas dan reliabilitas semangat kerja $(Y)$ semua item baik $Y 1.1$ sampai dengan $Y 1.8$ dikatakan valid sebab nilai r-hitung lebih besar dari pada nilai r-tabel dan dikatakan reliabel karena Cronbach's Alpha > 0,60.

\section{Uji Regresi Linear Berganda}

Dalam penggunaan analisis jalur (path analysis) diketahui variabel (independen) yakni variabel Mutasi $\left(X_{1}\right)$ dan Pengembangan Karir $\left(X_{2}\right)$ baik secara bersama-sama (simultan) dan sendiri-sendiri (parsial) memberikan pengaruh (signifikan) terhadap variabel terikat (dependen). Dari hasil olahan data untuk 53 responden dengan menggunakan analisis jalur maka diperoleh persamaan model sebagai berikut :

Tabel 4 : Regresi Linear Berganda

\begin{tabular}{|c|c|c|c|c|c|}
\hline \multirow[t]{2}{*}{ Model } & \multicolumn{2}{|c|}{ Unstandardized Coefficients } & \multirow{2}{*}{$\begin{array}{l}\text { Standardized } \\
\text { Coefficients }\end{array}$} & \multirow[t]{2}{*}{$\mathrm{T}$} & \multirow[t]{2}{*}{ Sig. } \\
\hline & $\mathrm{B}$ & Std. Error & & & \\
\hline (Constant) & 21780.827 & 2742.904 & & 7.941 & .000 \\
\hline $\mathrm{X} 1$ & .310 & .120 & .386 & 2.618 & .013 \\
\hline $\mathrm{x} 2$ & .245 & .140 & .353 & 2.588 & .030 \\
\hline
\end{tabular}

Sumber: Data Olahan 2021

$$
Y=0,386 X 1+0,353 \times 2+0,218 \varepsilon
$$

Dari persamaan analisis statistik diatas terdapat efek yang signifikan antara variabel mutasi sebagai variabel independen terhadap variabel semangat kerja. Artinya jika pada 
instansi tersebut dalam hal mutasi pegawai ditingkatkan tentunya berdampak pada peningkatan semangat kerja pegawai sebesar 0,386 atau 38,6 \%.

Variabel pengembangan karir terhadap variabel semangat kerja (Y) memiliki dampak yang signifikan. Artinya jika jika instansi tersebut pengembangan karir pegawai diperhatikan dan ditingkatkan tentunya semangat kerja pegawai juga turut mengalami peningkatan sebesar 0,353 atau 35,3\%

Dalam persamaan ini terdapat variabel yang tidak diteliti $(\varepsilon)$ tetapi ikut mempengaruhi semangat kerja $(Y)$ pegawai. Variabel yang tidak diteliti tersebut adalah kompensasi dengan besarnya pengaruh 0,218 atau $21,8 \%$

\section{Uji Korelasi}

Tabel 5 : Korelasi Antar Variabel X1 dan X2

\begin{tabular}{|c|c|c|c|}
\hline & & $\mathrm{X} 1.1$ & $\mathrm{X} 1.2$ \\
\hline \multirow{4}{*}{$\mathrm{X} 1.1$} & Pearson Correlation & 1 & 218 \\
\hline & Sig. (2-tailed) & & .091 \\
\hline & $\mathrm{N}$ & 53 & 53 \\
\hline & Pearson Correlation & 218 & 1 \\
\hline \multirow[t]{2}{*}{$\mathrm{X} 1.2$} & Sig. (2-tailed) & .091 & \\
\hline & $\mathrm{N}$ & 53 & 53 \\
\hline
\end{tabular}

Sumber: Data Olahan 2021

Berdasarkan hasil olahan data dengan menggunakan analisis jalur terdapat suatu korelasi antara variabel X1 dan X2 sebesar 0,218 atau $21,8 \%$

\section{Mengukur Uji Koefisien Determinasi}

Tabel 6 : Koefisien Determinasi

\begin{tabular}{|l|c|c|c|c|}
\hline Model & $\mathrm{R}$ & $\mathrm{R}$ Square & $\begin{array}{c}\text { Adjusted } \mathrm{R} \\
\text { Square }\end{array}$ & $\begin{array}{c}\text { Std. Error of the } \\
\text { Estimate }\end{array}$ \\
\hline 1 & $.825^{\mathrm{a}}$ & .782 & .771 & .812 \\
\hline
\end{tabular}

Sumber: Data Olahan 2021

Hasil analisis yang dapat diinterpretasikan bahwa koefisien determinasi (R Square) sebesar 0,812 atau 81,2 \% diartikan adanya kontribusi dampak mutasi (X1) dan pengembangan karir $(\mathrm{X} 2)$ terhadap semangat kerja $(\mathrm{Y})$. Sedangkan 21,8 \% adalah variabel diluar yang tidak diteliti. 


\section{Uji Hipotesis Simultansi}

Tabel 7 : Uji Hipotesis Simultan

\begin{tabular}{|c|c|c|c|c|c|c|}
\hline \multicolumn{2}{|c|}{ Model } & Sum of Squares & df & Mean Square & $\mathrm{F}$ & Sig. \\
\hline \multirow{3}{*}{1} & Regression & 249,102 & 2 & 41,202 & 45,540 & $.002^{b}$ \\
\hline & Residual & 33,241 & 51 & ,644 & & \\
\hline & Total & 282,343 & 53 & & & \\
\hline
\end{tabular}

Sumber: Data Olahan 2021

Riset ini mendapatkan uji $F_{\text {hitung }}$ mendapatkan hasil sebesar 45,540 lain halnya dengan $\mathrm{F}_{\text {tabel }}$ sebesar 2,78 dan propability sig $0,002<$ propability $\alpha=0,05$. Tentunya ini mengandung pengertian bahwa pada derajat kepercayaan $95 \%$, secara perhitungan statistik variabel Mutasi (X1) dan variabel Pengembangan Karir (X2) secara simultan (bersama-sama) memiliki dampak signifikan terhadap Semangat Kerja (Y) pada kantor Dinas Pengendalian Penduduk, Keluarga Berencana, Pemberdayaan Perempuan dan Anak (DPPKBP3A) Kota Gorontalo.

\section{Uji Hipotesis Parsial}

1. Dalam pengujian regresi Tabel 4 variabel mutasi $\left(X_{1}\right)$ memiliki nilai propability sig lebih kecil dari pada propability a $(0,013<0,05)$ pada taraf kepercayaan $95 \%$. Sehingga hipotesis untuk parsialnya, variabel mutasi $\left(X_{1}\right)$ mempunyai dampak signifikan terhadap semangat kerja ( $\mathrm{Y}$ )

2. Hasil pengujian regresi Tabel 4 variabel pengembangan karir $\left(X_{2}\right)$ memiliki nilai propability sig lebih lebih rendah dari pada propability $\alpha(0,030<0,05)$ pada taraf kepercayaan $95 \%$. Sehingga uji hipotesis yang menjelaskan bahwa pengembangan karir $\left(\mathrm{X}_{2}\right)$ secara parsial memiliki dampak signifikan terhadap semangat kerja $(\mathrm{Y})$.

\section{E. KESIMPULAN}

Dari hasil riset membuktikan melalui analisis dan uji statistik, dan penjelasan dalam pembahasan maka dapat ditarik suatu kesimpulan sebagai berikut : "Bahwa mutasi $\left(\mathrm{X}_{1}\right)$ dan Pengembangan Karir $\left(X_{2}\right)$ secara simultanya (bersama-sama) memiliki efek signifikan terhadap Semangat Kerja $(Y)$ pegawai pada kantor Dinas Pengendalian Penduduk, Keluarga Berencana, Pemberdayaan Perempuan dan Anak (DPPKBP3A) Kota Gorontalo, secara parsial Mutasi (X1) berefek signifikan terhadap semangat kerja (Y) pegawai pada kantor Dinas Pengendalian Penduduk, Keluarga Berencana, Pemberdayaan Perempuan dan Anak (DPPKBP3A) Kota Gorontalo, Pengembangan Karir (X2) secara parsial (sendiri-sendiri) memiliki pengaruh positif dan signifikan terhadap semangat kerja $(Y)$ pegawai pada kantor Dinas Pengendalian Penduduk, Keluarga Berencana, Pemberdayaan Perempuan dan Anak (DPPKBP3A) Kota Gorontalo".

"Disarankan kepada pihak instansi dalam hal ini Dinas Pengendalian Penduduk, Keluarga Berencana, Pemberdayaan Perempuan dan Anak (DPPKBP3A) Kota Gorontalo untuk dapat memperhatikan pengembangan karir pegawainya karena sesuai dengan hasil penelitan variabel tersebut memiliki pengaruh yang rendah sehingga dalam meningkatkan semangat kerja pegawai pihak pengambil kebijakan agar dapat memperhatikan pengembangan karir para pegawainya. Selanjutnya bagi para peneliti dikemudian hari turut berpartisipasi melaksanakan riset yang sama dengan lokasi berbeda mengenai semangat kerja pegawai atau karyawan kiranya dapat meneliti variabel lain yang mempengaruhi semangat kerja seperti upah dan budaya organisasi". 


\section{DAFTAR PUSTAKA}

Ambarita, dkk. 2015. Pengaruh Mutasi Terhadap Semangat Kerja Pegawai Negeri Sipil Pada Kantor Pelayanan Pajak Pratama Kota Pematang Siantar, Jurnal Perspektif, 8(2), 527-533, (http://www.ojs.uma.ac.id/index.php/perspektif/article/view/177/129)

Badriah. 2015. Manajemen Sumber Daya Manusia. Bandung: Pustaka Setia

Judas. (2013). Mutasi dan Promosi Jabatan Pengaruhnya Terhadap Prestasi Kerja Pegawai Pada Kanwil Ditjen Kekayaan Negara Sulutenggo dan Maluku Utara di Manado. Jurnal EMBA, 1219-1228. (https://ejournal.unsrat.ac.id/index.php/emba/article/view/2895/2446)

Kadim, A., Sunardi, N., Lesmana, R., \& Sutarman, A. (2019). Revitalisasi Fungsi Masjid Sebagai Pusat Penguatan Manajemen Peternak Sapi Rakyat melalui Lembaga Pemberdayaan Masyarakat Terpadu (LEMPERMADU).(Studi Kasus di Masjid Ainul Yaqin Kel. Jontlak, Kec. Praya, Kab. Lombok Tengah, Provinsi Nusa Tenggara Barat). Jurnal Abdi Masyarakat Humanis, 1(1).

Lesmana, R., Sunardi, N., \& Kartono. The Effect of Financing and Online Marketing on MSMEs Income Increasing at Intermoda Modern Market BSD City Tangerang Selatan. American Journal of Humanities and Social Sciences Research (AJHSSR), 5(7), 25-34

Lesmana, R., Sutarman, A., \& Sunardi, N. Building A Customer Loyalty Through Service Quality Mediated by Customer Satisfaction. American Journal of Humanities and Social Sciences Research (AJHSSR), 5(3), 38-45

Marpaung. 2018. Pengaruh Pengembangan Karir Terhadap Penilaian Prestasi Kerja (Studi Kasus Pada PT PLN (Persero) Wilayah Sumatera Utara, Jurnal IImiah Methonomi, 4(1), 79-86, (http://www.methonomi.net)

Negara. 2014. Pengaruh Pengembangan Karir Terhadap Kinerja Pegawai Pada PT Pos Indonesia (Persero) Kabupaten Jembran, Jurnal Pendidikan Indonesia (JPI), 4(1), 1-11, (https://ejournal.undiksha.ac.id)

Permaningratna. 2013. Pengaruh Lingkungan Kerja Fisik dan komunikasi Terhadap Semangat Kerja Karyawan, Jurnal Pendidikan Ekonomi Undiksha, 1(1), 1-6, (https://ejournal.undiksha.ac.id/index.php/JJPE/article/view/387/334)

Pramuditha. (2020). Analisis Mutasi dan Kompetensi Komunikasi Terhadap Prestasi Kerja Pegawai, Journal of Applied Business Administration (JABA), 4(2), 134-141 (https://jurnal.polibatam.ac.id/index.php/JABA/article/view/2032

Priansa. 2016. Perencanaan dan Pengembangan SDM. Bandung: Alfabeta.

Purwaningrum, dkk. 2014. Pengaruh Penilaian Kinerja Terhadap Semangat Kerja (Studi pada Karyawan Tetap PT. Agiomultimex), Jurnal Administrasi Bisnis (JAB), 8(2), 110,http://administrasibisnis.studentjournal.ub.ac.id/index.php/jab/article/view/360/55 $\underline{5}$

Ratnasari, dkk. 2017. Pengaruh Kepemimpinan Transformasional dan Lingkungan Kerja Terhadap Semangat Kerja Tenaga Kependidikan, Jurnal Inspirasi Bisnis \& Manajemen, $1(2)$,

99-112 (http://jurnal.unswagati.ac.id/index.php/jibm/article/view/665/537)

Rosidah. 2009. Manajemen Sumber Daya Manusi Konsep, Teori dan Pengembangan dalam Konteks Organisasi Publik. Yogyakarta: Graha Ilmu.

Samsudin. 2006. Manajemen Sumber Daya Manusia. Bandung: Pustaka Setia. 
Sari, Y.K. 2020. Pengaruh Motivasi Terhadap Semangat Kerja Pegawai Pada Kantor Balai Diklat Keuangan Palembang, Jurnal Nasional Manajemen Pemasaran \& SDM, 1(1), 54-64, (http://journal.jis-institute.org/index.php/jnmpsdm/article/view/8/11

Sugiyono. 2010. Metode Penelitian Pendidikan Pendekatan Kuantitatif, kualitatif, dan R\&D. Bandung: Alfabeta.

Sunardi, N., \& Lesmana, R. (2020). Konsep Icepower (Wiramadu) sebagai Solusi Wirausaha menuju Desa Sejahtra Mandiri (DMS) pada Masa Pandemi Covid19. JIMF (Jurnal IImiah Manajemen Forkamma), 4(1).

Wardana. 2015. Pengaruh Motivasi, Insentif, dan Pengembangan Karir Terhadap Kinerja Karyawan PT Telkomsel Grapari Pemuda Surabaya, e-Jurnal IImu Manajemen MAGISTRA, Vol 1(2), 1-12, (https://jurnal.narotama.ac.id)

Widodo. 2015. Manajemen Pengembangan Sumber Daya Manusi. Yogyakarta: Pustaka Pelajar. 